Article

\title{
Development of a High-Precision Touch-Trigger Probe Using a Single Sensor ${ }^{\dagger}$
}

\author{
Rui-Jun Li ${ }^{1,2}$, , Meng Xiang ${ }^{1}$, Ya-Xiong He ${ }^{1}$, Kuang-Chao Fan ${ }^{1,3}$, Zhen-Ying Cheng ${ }^{1}$, \\ Qiang-Xian Huang ${ }^{1}$ and Bin Zhou ${ }^{1,2}$ \\ 1 School of Instrument Science and Opto-electric Engineering, Hefei University of Technology, Hefei 230009, \\ China; xm0407@126.com (M.X.); yaxionghe@163.com (Y.-X.H.); fan@ntu.edu.tw (K.-C.F.); \\ chengzhenying2002@163.com (Z.-Y.C.); huangqx@hfut.edu.cn (Q.-X.H.); 000zhoubin000@163.com (B.Z.) \\ 2 Anhui Electrical Engineering Professional Technique College, Hefei 230051, China \\ 3 Department of Mechanical Engineering, National Taiwan University, Taipei 10617, Taiwan \\ * Correspondence: rj-li@hfut.edu.cn; Tel./Fax: +86-551-6290-3823 \\ $+\quad$ This paper is an extended version of paper published in the 9th International Symposium on Precision \\ Engineering, Measurements and Instrumentation conference (ISPEMI9), Changsha, China, 8-11 \\ August 2014.
}

Academic Editor: Chien-Hung Liu

Received: 30 January 2016; Accepted: 14 March 2016; Published: 18 March 2016

\begin{abstract}
To measure various components with nano-scale precision, a new high-precision touch-trigger probe using a single low-cost sensor for a micro-coordinate measuring machine (CMM) is presented in this paper. The sensor is composed of a laser diode, a plane mirror, a focusing lens, and a quadrant photo detector (QPD). The laser beam from the laser diode with an incident angle is reflected by the plane mirror and then projected onto the quadrant photo detector (QPD) via the focusing lens. The plane mirror is adhered to the upper surface of the floating plate supported by an elastic mechanism, which can transfer the displacement of the stylus's ball tip in 3D to the plane mirror's vertical and tilt movement. Both motions of the plane mirror can be detected by respective QPDs. The probe mechanism was analyzed, and its structural parameters that conform to the principle of uniform sensitivity and uniform stiffness were obtained. The simulation result showed that the stiffness was equal in $3 \mathrm{D}$ and less than $1 \mathrm{mN} / \mu \mathrm{m}$. Some experiments were performed to investigate the probe's characteristics. It was found that the probe could detect the trigger point with uniform sensitivity, a resolution of less than $5 \mathrm{~nm}$, and a repeatability of less than $4 \mathrm{~nm}$. It can be used as a touch-trigger probe on a micro/nano-CMM.
\end{abstract}

Keywords: touch-trigger probe; stiffness; quadrant photo detector; coordinate measuring machine

\section{Introduction}

With the development of various micro-fabrication technologies, many miniaturized structures and components with nano-scale precision have been produced in recent twenty years. Accordingly, many micro-/nano-coordinate measuring machines (micro-/nano-CMMs) have been proposed to satisfy the urgent demand for the dimensional measurement of micro parts [1-4]. Many touch probing systems that can be equipped onto micro-/nano-CMMs have also been developed, such as (a) the capacitive probe that uses at least three high-precision capacitive sensors to detect the arm's displacement of the floating plate of the probe $[5,6],(b)$ the strain gauge probe that adheres strain gauges on the membrane or cantilevers symmetrically to detect the ball tip's motion using the piezo-resistive effect [7-10], (c) the inductive probe that uses three high-precision inductive sensors and a complicated flexure hinges to construct the probe head [11], (d) the fiber probe that uses the imaging system to detect the ball tip's motion [12-14] or uses long Bragg gratings to detect the axial 
motion of the probe tip [15] or its 3D motion [16,17], and (e) the optical sensing probe that uses different optical principles to detect the probe motion, such as position detector, focus sensor, interferometer, auto-collimator, etc. [18-26]. Although all the above probes have good sensitivity, accuracy, resolution, repeatability, and stiffness, their permissible measurement ranges are limited since their adopted sensors do not tolerate a large tilt or a large translation of the probe tip. In addition, due to the use of multiple sensors for detecting 3D motions of the probe, their costs are still high.

The QPD (quadrant photo detector)-based angle sensor has high accuracy and high sensitivity, which has been verified in some probes [20,25,26], especially in Atomic Force Microscope (AFM) [23]. A new touch-trigger probe with a simple structure, small size, and low cost is proposed in this paper. Only one QPD-based two-dimensional angle sensor is used in this probe, which can simultaneously detect the trigger signals of the probe tip in 3D. Targets of the probe's design include: (1) that the permissible range of the probe is more than $\pm 6 \mu \mathrm{m}$; (2) that the probe has equal sensitivity and equal stiffness in three dimensions; (3) that the stiffness is less than $1 \mathrm{mN} / \mu \mathrm{m}$; (4) that the repeatability of trigger measurement is less than $5 \mathrm{~nm}(K=2)$; and (5) that the cross-sectional diameter is less than $40 \mathrm{~mm}$. The design principle and optimal parameters of the innovative touch-trigger probe are addressed in this paper. Experimental results also show the characteristics of the probe.

\section{Structure and Principle}

This touch trigger probe, shown in Figure 1, mainly consists of three components: a QPD-based sensor, a floating plate, and a tungsten stylus with a ruby ball tip. A plane mirror is adhered to the upper surface of the floating plate. The stylus is mounted on the center position on the lower surface of the floating plate. Four V-shaped leaf springs, fixed to the probe housing, are designed to connect the floating plate. When a contact force is applied to the ball tip of the stylus, the floating plate and the stylus perform a rigid body motion. Simultaneously, the four leaf springs yield corresponding elastic deformations by the floating plate, and the plane mirror on the floating plate tilts along horizontal axes or displaced in the vertical axis. The probe housing is made of an aluminum cylinder. The QPD, the focus lens, and the circuit board are imbedded in the probe. A laser diode is placed on an adjusting mechanism whose elastic component is formed by folding a beryllium-copper alloy sheet. The adjusting mechanism is applied to assure the reflected laser beam being focused onto the centre of the QPD in the initial state.

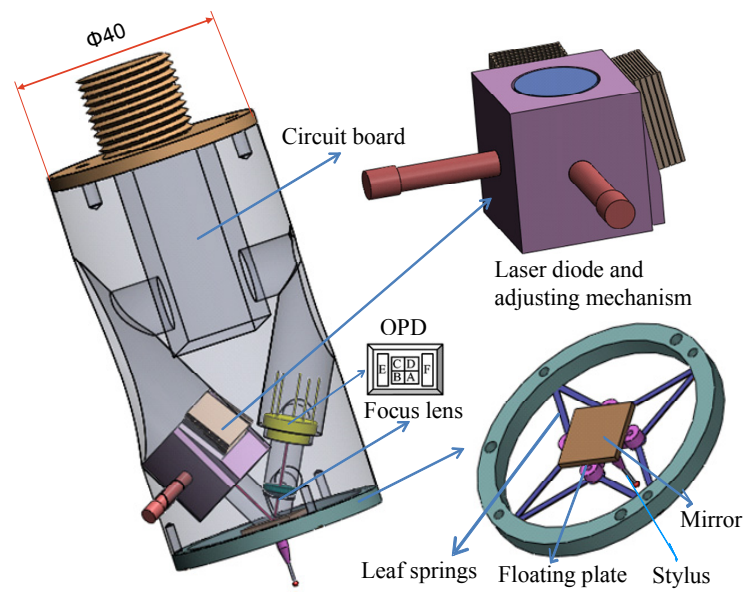

Figure 1. The sketch map of the probe.

Figure 2 shows the optical path of the sensor system, which is composed of a laser diode, a plane mirror, a focusing lens, and a QPD. The laser beam from the laser diode with an incident angle is reflected by the plane mirror and then projected onto the QPD via the focusing lens. A tilt angle or a vertical displacement of the plane mirror causes a lateral shift of the focused light spot on the QPD. 
The QPD outputs the light energy of each quadrant photo detector into an electrical current signal. By applying an appropriate resistance to these current signals, four output voltage signals $\left(V_{\mathrm{A}}, V_{\mathrm{B}}\right.$, $V_{\mathrm{C}}$, and $V_{\mathrm{D}}$ ) can be obtained. Two-dimensional shifts of the focused light spot caused by the motion of the plane mirror can be expressed by Equations (1) and (2), in which $k_{1}$ and $k_{2}$ are constants [26]. When the ball tip is contacted in any direction by the workpiece, the probe generates a trigger signal at the same time.

$$
\begin{aligned}
& x=k_{1}\left[\left(V_{A}+V_{D}\right)-\left(V_{B}+V_{C}\right)\right] \\
& y=k_{2}\left[\left(V_{A}+V_{B}\right)-\left(V_{C}+V_{D}\right)\right]
\end{aligned}
$$

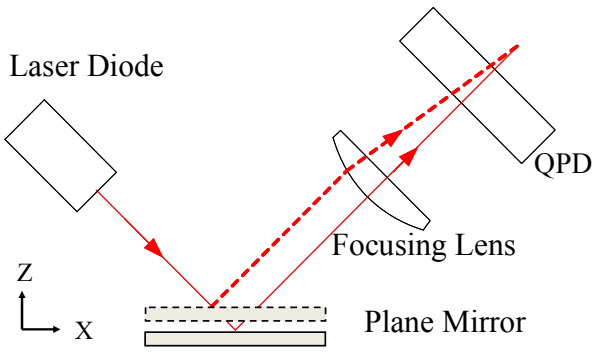

(a)

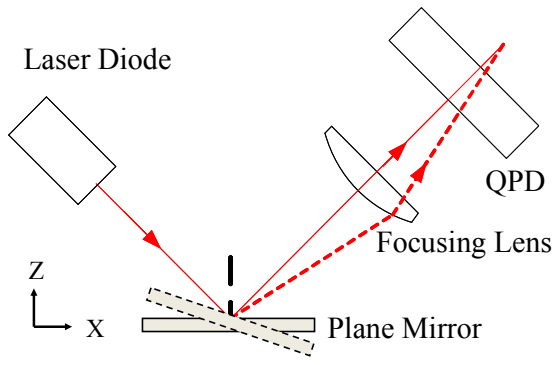

(b)

Figure 2. Optical paths of the sensor. (a) Mirror in vertical displacement and (b) mirror in tilt motion.

\section{Analysis and Design of the Probe}

\subsection{The Sensitivity Analysis}

The principle of detecting the Z-motion of the probe, when the ball tip is touched along this direction, is shown in Figure 3. The optical beam with an incidence angle of $\alpha$ is reflected by the plane mirror and focused onto the QPD. The reflected beam is shifted from point $\mathrm{D}$ to point $\mathrm{E}$ on the focusing lens, and the focused spot is shifted from point $B$ to point $C$ on the QPD if the QPD is placed in front of the focal point of the lens. From the geometrical relationship in Figure 3, we have $\sin \alpha=(\overline{F G} / \overline{F H})$ and $\overline{F G}=\delta_{v}\left(\delta_{\mathrm{v}}\right.$ is the vertical displacement of the probe tip). The line of FI is perpendicular to the line of $\mathrm{AH}$ so that

$$
\sin \angle F H I=\sin (\pi-2 \alpha)=\sin (2 \alpha)=\overline{F I} / \overline{F H}
$$

Therefore,

$$
\overline{D E}=\overline{F I}=2 \cdot \delta_{v} \cdot \cos \alpha
$$

Because $(\overline{A D} / \overline{A B})=(\overline{D E} / \overline{B C})$, and $\overline{A D}$ (the focal length of the focusing lens) and $\overline{B D}$ are donated by $f$ and $m$, respectively, we have

$$
\overline{B C}=2 \cdot \delta_{v} \cdot(1-m / f) \cdot \cos \alpha
$$

The output voltage $\left(U_{v}\right)$ from QPD is proportional to the displacement of the focused spot $(\overline{B C})$, namely, $U_{v}=k \cdot \overline{B C}$ and $k$ is a constant. Therefore, the sensitivity in the vertical direction can be obtained as:

$$
S_{v}=U_{v} / S_{v}=2 k \cdot(1-m / f) \cdot \cos \alpha
$$




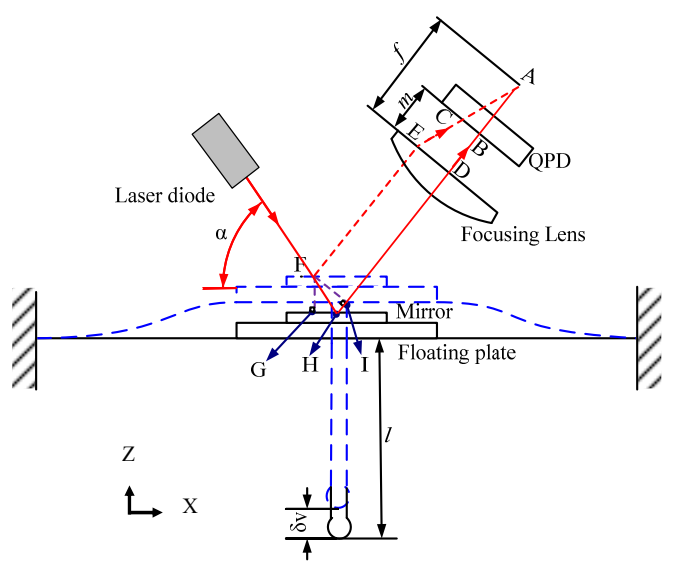

Figure 3. Detecting principle of the probe in Z-motion.

In the same way, the principle of the detecting probe in a horizontal tilt motion, when the probe tip is touched in the horizontal direction and results in a $\delta_{h}$ displacement is shown in Figure 4. The rotated angle and the length of the stylus are denoted as $\theta$ and $l$, respectively. From the geometrical relationship of the optical path, we have $\overline{M N} \approx \overline{D E}$ and $\overline{O N} \approx \overline{O D}=n$. Because, in practice, $\theta$ is very small, it is assumed $\sin \theta=\left(\delta_{h} / l\right) \approx \theta$. The stylus and the floating plate can be regarded as a rigid body and $\angle N O M=2 \theta$, so that

$$
\begin{gathered}
\tan 2 \theta=(\overline{M N} / \overline{O N})=(\overline{D E} / n) \approx 2 \theta \\
\overline{D E}=2 n \delta_{h} / l
\end{gathered}
$$

Because $\overline{A B} / \overline{A D}=\overline{B C} / \overline{D E}=(f-m) / f$ and $U_{h}=k \cdot \overline{B C}$, the horizontal sensitivity can be obtained:

$$
S_{h}=U_{h} / \delta_{h}=(2 n k / l) \cdot(1-m / f)
$$

In order to have the characteristic of uniform sensitivity, we can let Equation (6) be equal to Equation (9), yielding:

$$
\cos \alpha=n / l
$$

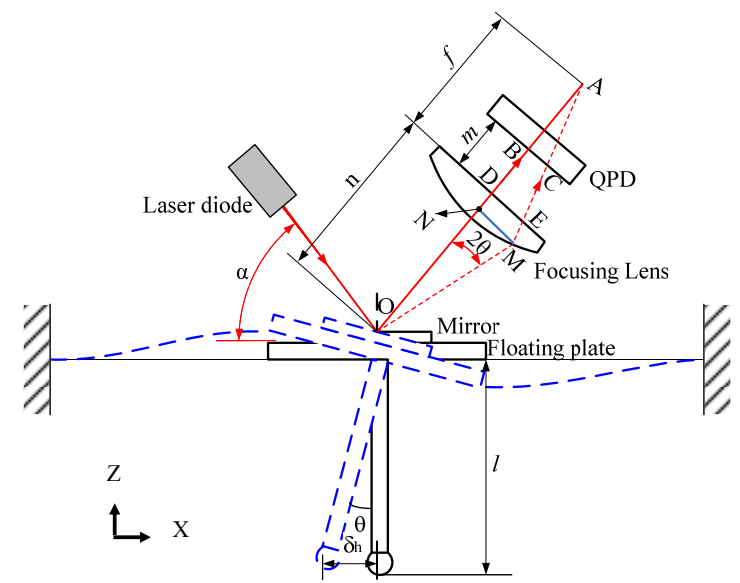

Figure 4. Detecting principle of the probe in horizontal tilt motion.

\subsection{The Stiffness Analysis}

The free-body diagram of the floating plate is illustrated in Figure 5. T, $P, M, F$ are torque, shear force, bending moment, and contact force, respectively. The characteristics of this probe between 
the contact force and the ball tip's motion were analyzed, and the stiffness models in horizontal and vertical directions are as follows [26,27].

$$
\begin{gathered}
K_{y}=F_{y} / \delta_{b, y}=\frac{4}{L^{3} l^{2}}\left[G J L^{2}+2 E I\left(6 r^{2}+3 r \sin \beta+3 r L \sin \beta+L\right)+2 E I\left(6 a^{2}+3 a \cos \beta+3 a L \cos \beta+L\right)\right] \\
\mathrm{K}_{Z}=\frac{F_{Z}}{\delta_{b, Z}}=\frac{96 E I}{L^{3}}
\end{gathered}
$$

where $I=\frac{w t^{3}}{12}, \mathbf{J}=\frac{w t^{3}}{16}\left(\frac{16}{3}-3.36 \frac{t}{w}\right)$, and $G=\frac{E}{2(1+v)} ; t, w$, and $L$ are the thickness, width, and length of the leaf springs, respectively; $E$ and $v$ are Young's modulus and Poisson's ratio of the leaf springs, respectively; $l$ is the length of the stylus; $r$ is the arm length of the floating plate; and $a$ is one-half of the arm width.

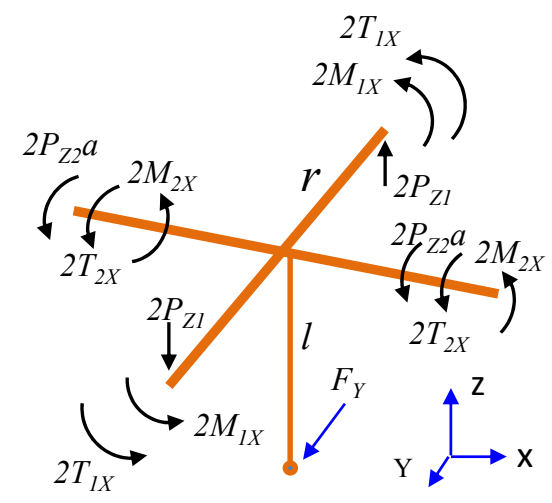

Figure 5. Free-body diagram of the floating plate.

\subsection{Optimal Design for the Probe}

The optimal parameters of the probe (see Table 1) have been evaluated according to the constrained conditions that the limited stiffness should be less than $1 \mathrm{mN} / \mu \mathrm{m}$, i.e., $K_{v}=K_{h} \leqslant 1 \mathrm{mN} / \mu \mathrm{m}$, and the maximum cross-sectional diameter of the probe head should be smaller than $40 \mathrm{~mm}$.

Table 1. The parameters of the probe.

\begin{tabular}{cc}
\hline Parameter & Value \\
\hline Material of the leaf springs & beryllium-copper alloy \\
Young's modulus of the leaf springs $(\mathrm{GPa})$ & 130 \\
Leaf thickness $\times$ width $\times$ length $(\mathrm{mm})$ & $0.1 \times 2 \times 13$ \\
Material of the floating plate & aluminum alloy \\
Young's modulus of the floating plate $(\mathrm{GPa})$ & 71 \\
floating plate arm thickness $\times$ width $\times$ length $(\mathrm{mm})$ & $1.5 \times 2 \times 5.5$ \\
Weight of the floating plate $(\mathrm{g})$ & 0.2 \\
Material of the stylus & 193 \\
Young's modulus of the stylus $(\mathrm{GPa})$ & 10 \\
Length of the stylus $(\mathrm{mm})$ & 0.5 \\
Diameter of the ball tip $(\mathrm{mm})$ & tungsten stylus with a ruby ball tip \\
\hline
\end{tabular}

Moreover, based on the constrained conditions of uniform sensitivity (Equation 10) and the measurement range being at least $\pm 6 \mu \mathrm{m}$, the other optimal parameters have also been obtained as: $\alpha=53^{\circ}, f=9.8 \mathrm{~mm}, n=6 \mathrm{~mm}$, and $m=4.9 \mathrm{~mm}$.

A finite element analysis for the probe was also performed using ANSYS V15 software (Ansys Inc, Canonsburg, PA, USA, 2014) so as to verify the stiffness model. The parameters listed in Table 1 were used. Structural deformations are shown in Figure $6 \mathrm{a}, \mathrm{b}$ when $1 \mathrm{mN}$ of force is applied in the 
vertical and horizontal directions, respectively. The resulting tip displacement of nearly $1 \mu \mathrm{m}$ is almost the same in both directions, corresponding to a uniform stiffness of $0.926 \mu \mathrm{m}$. Figure $6 \mathrm{c}$ illustrates the uniformity of the probe's stiffness along the $X-Y$ plane. In addition, the experimental verification for the stiffness of the floating mechanism was also conducted using a high sensitivity force sensor [26]. The stiffness measurements were $0.954 \mathrm{~N} / \mathrm{mm}$ in the Z-direction and $0.927 \mathrm{~N} / \mathrm{mm}$ in the horizontal direction, which is quite consistent with the finite element analysis and analytical results [27].

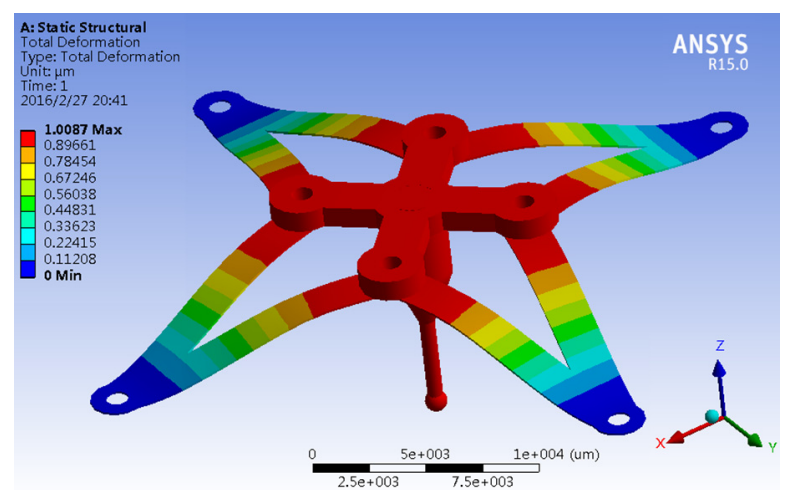

(a)

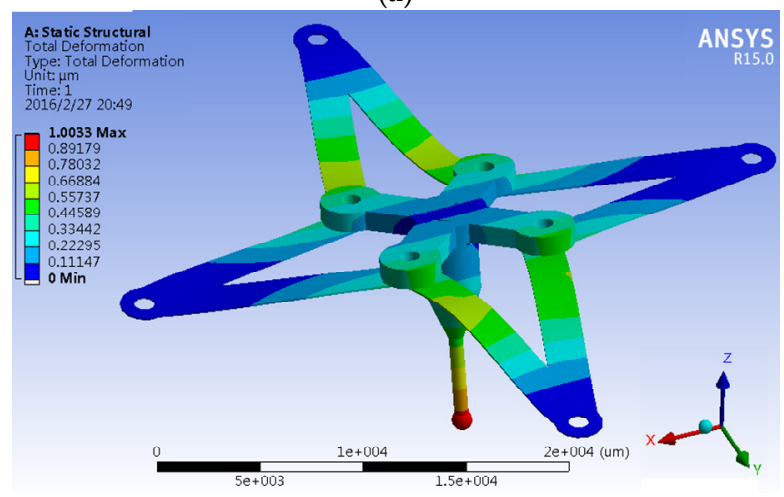

(b)

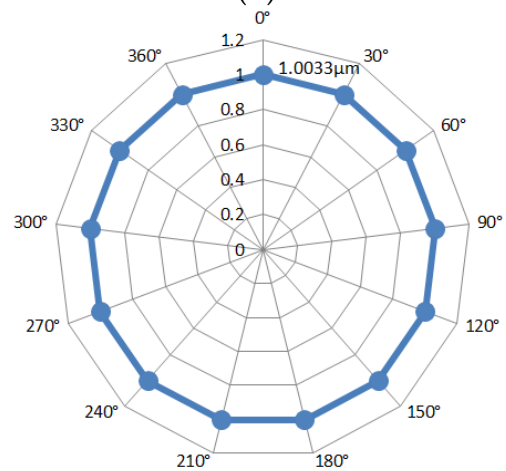

(c)

Figure 6. The tip's displacements when being touched by $1 \mathrm{mN}$ force. (a) Touched in $Z$ direction; (b) touched in $Y$ direction and (c) touched with a different angle in $X Y$ plane.

\section{Experimental Results and Discussion}

In order to test the performance of the designed probe, an experimental setup was carried out. As shown in Figure 7, a stable stand frame was used to hold the probe. Four high accuracy gauge blocks were used to form a $2 \mathrm{~mm} \times 2 \mathrm{~mm}$ square hole, which was able to contact the ball tip from different horizontal directions. A ball tip of $1 \mathrm{~mm}$ diameter was adopted. The clamped set of gauge blocks were mounted on a high-precision 3D nano-positioning stage made by Physik Instrumente (PI, 
model P-561.3CD with a repeatability of $2 \mathrm{~nm}$ and a distance of travel of $100 \mu \mathrm{m}$ in each direction, Physik Instrumente Co. Ltd., Karlsruhe, Germany). A normal 2D high-precision stage was used to manually adjust the initial position of the square hole. A Data Acquisition (DAQ) card from National Instruments (PCI-6251, National Instruments Co. Ltd., Austin, TX, USA) was use to recorded the voltage signals from the angle sensor.

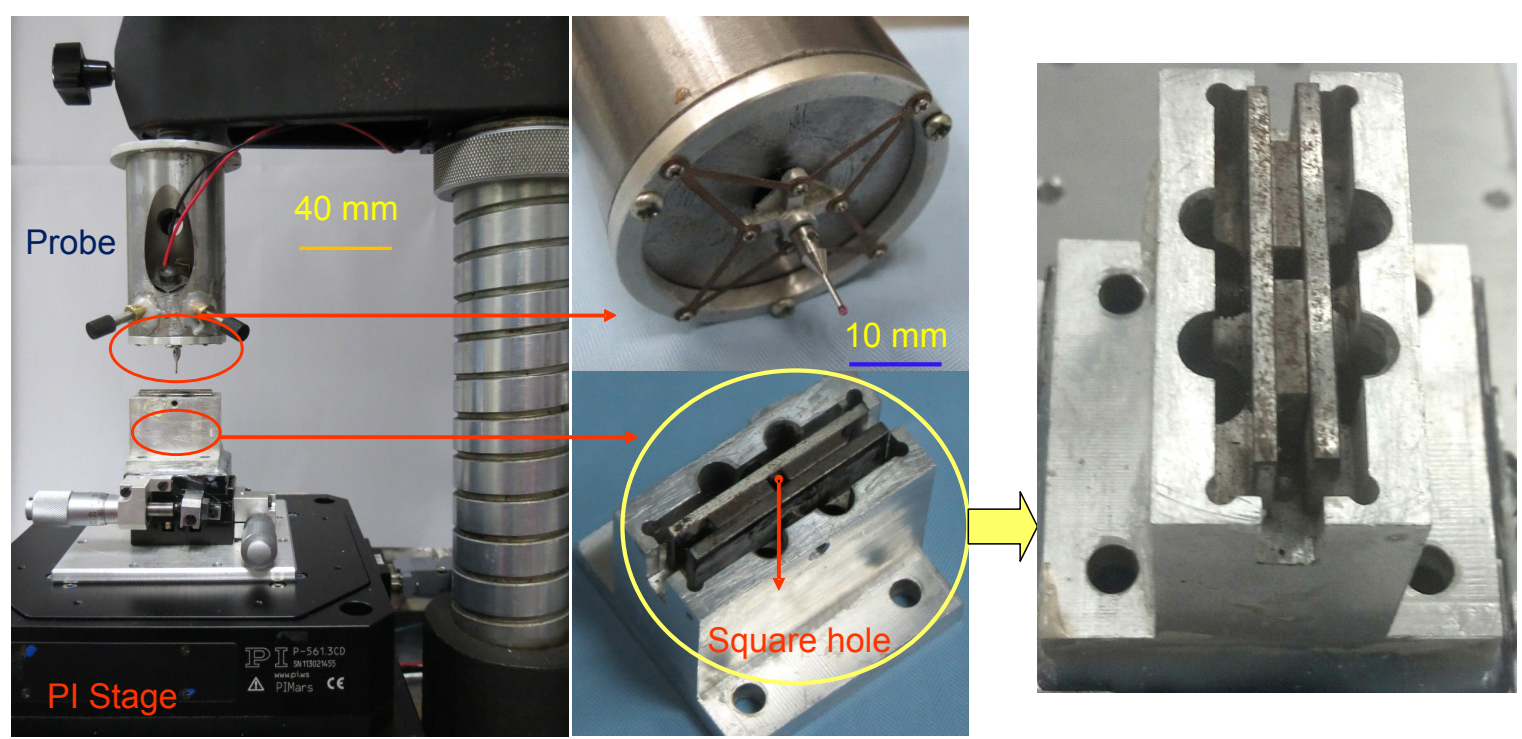

Figure 7. Photo of the experimental setup.

\subsection{Probe Drift}

In order to reduce the influence of the environmental temperature fluctuation, a low-cost vibration-free constant-temperature mini chamber was developed by our group [28,29]. The experimental setup, as shown in Figure 7, was put in the chamber, and the probe was adjusted to output a non-zero value. The stability of the probe was not investigated until the temperature in the chamber had been stabilized to within $20 \pm 0.05^{\circ} \mathrm{C}$, as shown in Figure 8 . Figure 9 shows the stability test results of the probe. It can be seen that the total drift of the probe was less than $5 \mathrm{~nm}$ for duration of three hours, and the fluctuation was less than $3 \mathrm{~nm}$ after two hours. The stability of the probe is thus confirmed.

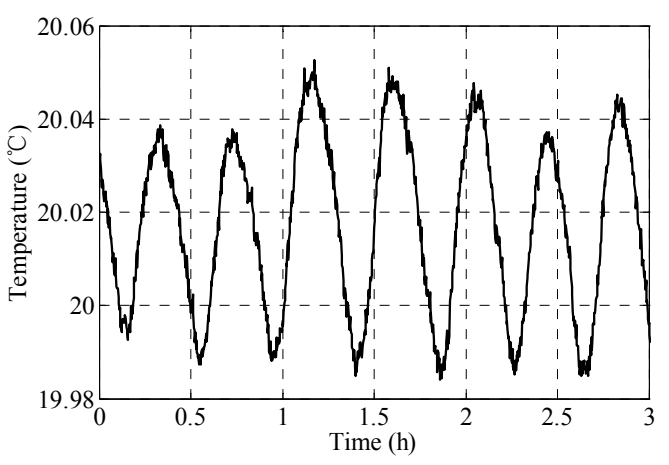

Figure 8. The temperature in the chamber. 


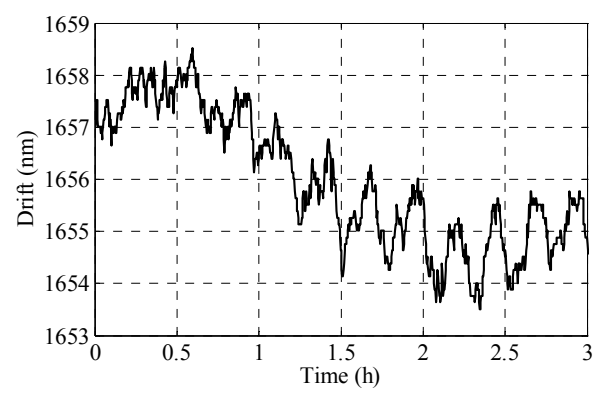

Figure 9. Stability test results of the probe.

\subsection{Probe Repeatability}

The touch-trigger repeatability of the probe along $X_{+}, X_{-}, Y_{+}, Y_{-}$, and $Z$ directions was also tested. The probe was touched seven times in each direction with a displacement of $1 \mu \mathrm{m}$ of the Physik Instrumente (PI) stage after the temperature in the chamber had stabilized. The residual errors of the test results in each direction are shown in Table 2 . The maximum single directional repeatability was $4 \mathrm{~nm}(K=2)$.

Table 2. Results of the trigger test.

\begin{tabular}{cccccc}
\hline \multirow{2}{*}{ Item } & \multicolumn{5}{c}{ Residual Errors (nm) } \\
\cline { 2 - 6 } & $\boldsymbol{X +}$ & $\boldsymbol{X}-$ & $\boldsymbol{Y}+$ & $\boldsymbol{Y}-$ & $\mathrm{Z}$ \\
\hline 1st & -0.6 & -1.1 & -2.7 & -1.4 & -1.9 \\
2nd & 2.9 & -0.8 & 0.2 & 1.3 & -1.4 \\
3rd & 0.6 & 1.9 & -1.8 & -0.3 & -1.2 \\
4th & -2.2 & 0.7 & 1.6 & 1.3 & 0.1 \\
5th & 0.6 & -2.6 & 2.1 & 0.7 & -2.4 \\
6th & -3.2 & 0.8 & 0.1 & -0.3 & -2.8 \\
7th & 1.3 & 2.0 & 1.2 & -1.0 & -1.0 \\
standard deviation & 2.0 & 1.7 & 1.8 & 1.1 & 1.0 \\
repeatability $(K=2)$ & 4.0 & 3.4 & 3.6 & 2.2 & 2.0 \\
\hline
\end{tabular}

\subsection{Sensitivity and Permissible Range}

Figure 10 shows the sensitivity and permissible range of the probe. It can be found that the sensitivities of the probe in horizontal and vertical directions were nearly equal and coincident with the design target quite well when the ball tip's displacement was within $1 \mu \mathrm{m}$. In other words, the probe has a uniform sensitivity within a trigger range of $1 \mu \mathrm{m}$ that is large enough for the touch-trigger measurement. Figure 10 also illustrates that the probe has a permissible range up to $8 \mu \mathrm{m}$, which provides a large safety margin for the application of the probe. The difference between two sensitivity curves could be caused by the error of manufacturing and assembly.

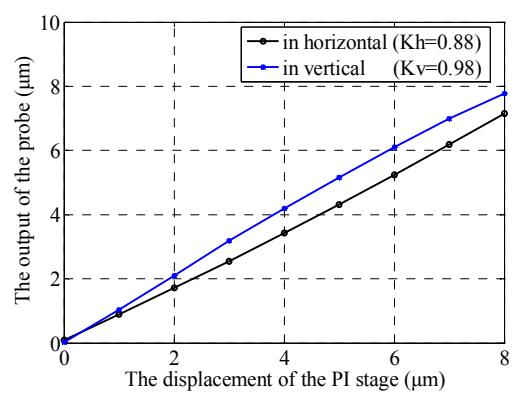

Figure 10. The sensitivity and permissible range of the probe. 


\subsection{Probe Resolution}

An experiment in the same condition as the repeatability test was carried out to investigate the resolution of the probe and the result is shown in Figure 11. The probe ball tip was pushed three steps by the gauge block with a step of $5 \mathrm{~nm}$ actuated by the PI stage and then returned back to the initial position. The steps of the probe precisely follow the motion command. Therefore, we can say that the probe has a resolution of less than $5 \mathrm{~nm}$. The different outputs of the probe tip between the beginning and the end might have been caused by the short periodic fluctuation shown in Figure 9.

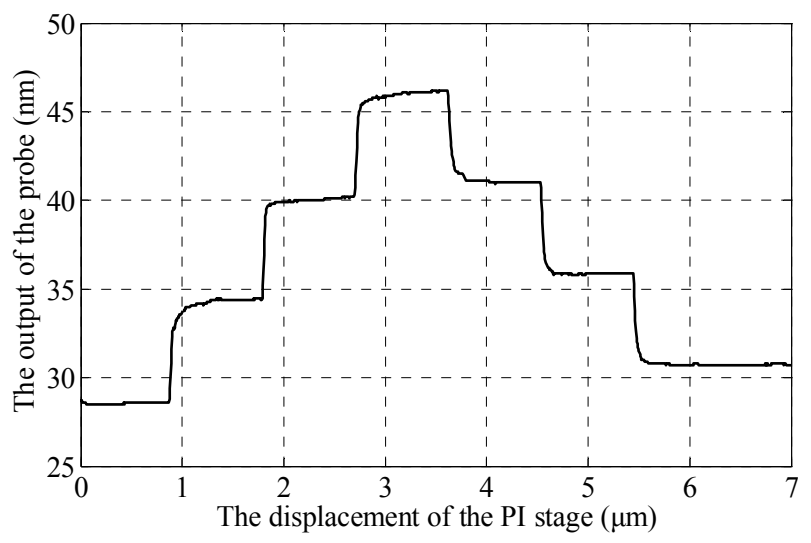

Figure 11. Resolution test results of the probe.

\section{Conclusions}

A new touch-trigger probe with a small single low-cost sensor for micro-CMMs is presented in this paper. The components and sensing principle of the probe were addressed. The sensitivity of the probe was analyzed, and the uniform sensitivity feature was obtained. The optimal structural parameters conforming to uniform stiffness were obtained. Finite element analysis and experiments were conducted. The probe was verified as having equal stiffness of less than $1 \mathrm{mN} / \mu \mathrm{m}$ in three dimensions, single-direction repeatability of less than $4 \mathrm{~nm}$, resolution better than $5 \mathrm{~nm}$ and a small cross-sectional diameter of $40 \mathrm{~mm}$.

Acknowledgments: The reported work is partly funded by the Natural Science Foundation of Anhui Province for Higher Education Institutions (KJ2015A410), the State Key Laboratory of Precision Measuring Technology and Instruments of China (PIL1401), the National Natural Science Foundation of China $(51475131,51475133)$ and the Foundation of Anhui Electrical Engineering Professional Technique College (2015zdxm05, 2015zdxm06).

Author Contributions: Rui-Jun Li and Kuang-Chao Fan conceived, designed the probe and wrote the paper; Meng Xiang performed the experiments and simulations; Ya-Xiong He manufactured the sensor; Qiang-Xian Huang designed the experiments; Zhen-Ying Cheng analyzed the sensitivity; Bin Zhou created the figures.

Conflicts of Interest: The authors declare no conflict of interest.

\section{Abbreviations}

The following abbreviations are used in this manuscript:

$\mathrm{CMM}$

Coordinate measuring machine

QPD

Quadrant photo detector

PI

Physik Instrumente

\section{References}

1. McKeown, P. Nanotechnology-Special Article. In Proceedings of the Nano-Metrology in Precision Engineering, Hong Kong, China, 24-25 November 1998; pp. 45-55. 
2. Fan, K.C.; Fei, Y.T.; Yu, X.F.; Chen, Y.J.; Wang, W.L.; Chen, F.; Liu, Y.S. Development of a low-cost micro-CMM for 3D micro/nano measurements. Meas. Sci. Technol. 2006, 17, 524-532. [CrossRef]

3. Jäeger, G.; Manske, E.; Hausotte, T. Nanopositioning and Measuring Machine. In Proceedings of the 2nd European Society for Precision Engineering and Nanotechnology, Turin, Italy, 28 May-1 June 2001; pp. 290-293.

4. Takamasu, K.; Furutani, K.R.; Ozono, S. Development of Nano-CMM (Coordinate Measuring Machine with Nanometer Resolution). In Proceedings of the XIV IMEKO World Congress, Tampere, Finland, 1-6 June 1997; pp. 34-39.

5. Peggs, G.N.; Lewis, A.J.; Oldfield, S. Design for a compact high-accuracy CMM. CIRP Ann. 1999, 48, 417-420. [CrossRef]

6. Leach, R.K.; Murphy, J. The Design of Co-Ordinate Measuring Probe for Characterizing Truly Three-Dimensional Micro-Structures. In Proceedings of the 4th EUSPEN International Conference, Glasgow, UK, 30 May-3 June 2004; pp. 230-231.

7. Dai, G.L.; Bütefisch, S.; Pohlenz, F.; Danzebrink, H.U. A high precision micro/nano CMM using piezoresistive tactile probes. Meas. Sci. Technol. 2009, 20, 1118-1121. [CrossRef]

8. Haitjema, H.; Pril, W.O.; Schellekens, P. Development of a silicon-based nano probe system for 3-D measurements. CIRP Ann. 2001, 50, 365-368. [CrossRef]

9. Peiner, E.; Balke, M.; Doering, L.; Brand, U. Tactile probes for dimensional metrology with micro components at nanometre resolution. Meas. Sci. Technol. 2008, 19, 579-588. [CrossRef]

10. Tibrewala, A.; Phataralaoha, A.; Büttgenbach, S. Development, fabrication and characterization of a 3D tactile sensor. J. Micromech. Microeng. 2009, 19, 125005-125009. [CrossRef]

11. Küng, A.; Meli, F.; Thalmann, R. Ultraprecision micro-CMM using a low force 3D touch probe. Meas. Sci. Technol. 2005, 18, 319-327. [CrossRef]

12. Hughes, E.B.; Wilson, A.; Peggs, G.N. Design of high accuracy CMM based on multilateration techniques. CIRP Ann. 2000, 49, 391-394. [CrossRef]

13. Muralikrishnan, B.; Stone, J.A.; Stoup, J.R. Fiber deflection probe for small hole metrology. Precis. Eng. 2006, 30, 154-164. [CrossRef]

14. Kim, S.W. New design of precision CMM based upon volumetric phase-measuring interferometry. CIRP Ann. 2001, 50, 357-360. [CrossRef]

15. Ji, H.; Hsu, H.Y.; Kong, L.X.; Wedding, A.B. Development of a contact probe incorporating a Bragg grating strain sensor for nano coordinate measuring machines. Meas. Sci. Technol. 2009, 20. [CrossRef]

16. Ding, B.Z.; Fei, Y.T.; Fan, K.C. 3D Touch Trigger Probe Based on Fiber Bragg Gratings. In Proceedings of the Metrology, Inspection and Process Control for Microlithography XXIII, San Jose, CA, USA, 19-20 January 2009.

17. Liu, F.F.; Fei, Y.T.; Xia, H.J.; Chen, L.J. A new micro/nano displacement measurement method based on a double-fiber Bragg grating (FBG) sensing structure. Meas. Sci. Technol. 2012, 23, 54002-54010. [CrossRef]

18. Enami, K.; Kuo, C.C.; Nogami, T.; Hiraki, M.; Takamasu, K.; Ozono, S. Development of nano-Probe System Using Optical Sensing. In Proceedings of the IMEKO-XV World Congress, Osaka, Japan, 13-18 June 1999; pp. 189-192.

19. Fan, K.C.; Cheng, F.; Wang, W.L.; Chen, Y.J.; Lin, J.Y. A scanning contact probe for a micro-coordinate measuring machine (CMM). Meas. Sci. Technol. 2010, 21, 603-616. [CrossRef]

20. Chu, C.L.; Chiu, C.Y. Development of a low-cost nanoscale touch trigger probe based on two commercial DVD pick-up heads. Meas. Sci. Technol. 2007, 18, 1831-1842. [CrossRef]

21. Liebrich, T.; Knapp, W. New concept of a 3D-probing system for micro-components. CIRP Ann. 2010, 59, 513-516. [CrossRef]

22. Balzer, F.G.; Hausotte, T.; Dorozhovets, N.; Manske, E.; Jäger, G. Tactile 3D microprobe system with exchangeable styli. Meas. Sci. Technol. 2011, 22, 94018-94024. [CrossRef]

23. Joonh, Y.K.; Jae, W.H.; Yong, S.K.; Lee, D.Y.; Lee, K. Atomic force microscope with improved scan accuracy, scan speed, and optical vision. Rev. Sci. Instrum. 2003, 74, 4378-4383.

24. Li, R.J.; Fan, K.C.; Huang, Q.X.; Qian, J.Z.; Gong, W.; Wang, Z.W. Design of a large scanning range contact probe for nano-coordinate measurement machines (CMM). Opt. Eng. 2012, 51, 527-529. [CrossRef]

25. Li, R.J.; Fan, K.C.; Miao, J.W.; Huang, Q.X.; Tao, S. An analogue contact probe using a compact 3D optical sensor for micro/nano coordinate measuring machines. Meas. Sci. Technol. 2014, 25, 1-33. [CrossRef] 
26. Li, R.J.; Fan, K.C.; Huang, Q.X.; Zhou, H.; Gong, E.M. A long-stroke 3D contact scanning probe for micro/nano coordinate measuring machine. Precis. Eng. 2015, 43, 220-229. [CrossRef]

27. Li, R.J.; Fan, K.C.; Zhou, H.; Wang, N.; Huang, Q.X. Elastic mechanism design of the CMM contact probe. In Proceedings of the SPIE, Chengdu, China, 8-11 August 2013; pp. 182-185.

28. Feng, J.; Li, R.J.; Fan, K.C.; Zhou, H.; Zhang, H. Development of a low-cost and vibration-free constant-temperature chamber for precision measurement. Sens. Mater. 2015, 27, 329-340. [CrossRef]

29. Li, R.J.; Fan, K.C.; Qian, J.Z.; Huang, Q.X.; Gong, W.; Miao, J.W. Stability analysis of contact scanning probe for micro/nano coordinate measuring machine. Nanotechnol. Precis. Eng. 2012, 10, 125-131.

(C) 2016 by the authors; licensee MDPI, Basel, Switzerland. This article is an open access article distributed under the terms and conditions of the Creative Commons by Attribution (CC-BY) license (http://creativecommons.org/licenses/by/4.0/). 